\title{
Improving Computer Literacy of Business Management Majors: A Case Study
}

\author{
David W. Johnson, Kimberly W. Bartholomew, Duane Miller \\ Utah Valley State College, Orem, Utah, USA
}

\section{johnsoda@uvsc.edu barthoki@uvsc.edu millerdu@uvsc.edu}

\section{Executive Summary}

Stakeholders, such as future employers, parents, and educators, have raised their expectations of college graduates in the area of computer literacy. Computer skills and understanding are especially critical for business management graduates, who are expected to use computer technology as a tool in every aspect of their career. Business students should be able to show an enhanced understanding of computer literacy as they progress through each year of their college experience. An ideal final assessment should show that these students are able to make use of their computer skills in high-level problem solving situations.

At the institution in this study, Utah Valley State College (UVSC), business management majors are required to complete a computer competency requirement early in their program by either taking a comprehensive computer applications course or by passing a state-wide computer proficiency exam. Later in their junior or senior year, these business students take a Management Information Systems (MIS) course where they are again expected to complete targeted business problems using spreadsheet, database, word processing, or presentation applications. These assigned business problems begin to approach the level of problem-solving expected by future employers. Instructors of the MIS course were seeing a lack of preparation and understanding as business management majors attempted to complete the assigned problems.

Objective and subjective computer competency evaluations were given to business management students during their freshman, junior, and senior years. The result of these evaluations showed a decrease in students' skill level and confidence level in some of the key computer literacy areas by graduation. When current or future employers were asked what computer literacy skills were most needed in business graduates, they ranked word processing and spreadsheet skills highest. In order to narrow the focus of this case study, spreadsheet use and confidence was singled out because this was the area in which our students seemed to need the most reinforcement and was highly valued by our local employers. At a future time, the participants of this study plan to extend this evaluation into other computer competency areas.

A literature review was conducted to determine possible courses of action that could be taken to

Material published as part of this journal, either on-line or in print, is copyrighted by the Informing Science Institute. Permission to make digital or paper copy of part or all of these works for personal or classroom use is granted without fee provided that the copies are not made or distributed for profit or commercial advantage AND that copies 1) bear this notice in full and 2) give the full citation on the first page. It is permissible to abstract these works so long as credit is given. To copy in all other cases or to republish or to post on a server or to redistribute to lists requires specific permission and payment of a fee. Contact Publisher@InformingScience.org to request redistribution permission. address the poor retention and advancement of some of the key computer literacy skills in business management majors. After examining our school's goals and constraints, we formulated a change management plan that would help move our students from their novice use of computer skills into the intermediate or advanced application of spreadsheets, which was the most deficient area iden- 
Improving Computer Literacy of Business Management Majors

tified by current employers of our graduates.. The six-step change management plan is outlined in this paper. An ongoing assessment of senior business management students will be conducted yearly and a follow-up study will report these results after two years. Although the approach taken at our institution to address the computer skill retention problem is specific to our needs, it is hoped that the framework provided here will aid others who are seeking to address similar problems in their programs.

Keywords: Computer proficiency, computer literacy, business students, improvement process

\section{Introduction}

A recent study by School of Business faculty members at Utah Valley State College (UVSC) found that there was a decrease in students' level of computer literacy in some areas as students moved from their freshman year to their senior year. Findings further suggested that these students had minimal requirements to use computer technology (other than word processing and presentation software) in their core business classes. This paper further describes these findings and presents a procedural framework developed by the authors for improving students' computer literacy before they enter the job market.

Different groups of people--students, teachers, and employers--have different ideas about what computer literacy means. In fact, these definitions of computer literacy have evolved with time as technology improved and society became more dependent on computers (Hoffman \& Blake, 2003). Some 50 years ago when a computer nearly filled a room, computer literacy meant being able to program a computer. Today, when the vast majority of households own one or more personal computers that fit on a desk top or on a lap, the definition of "computer literacy" has much less to do with programming and much more to do with using the computer. Owens (2003) identifies database concepts, general computer concepts, Internet concepts, presentations, spreadsheets, web authoring, word processing, and ethics as key areas of computer literacy. Other definitions of computer literacy focus on two areas: "whatever a person needs to know and do with computers in order to function competently in our society" and "a measure of competency to exploit computer technology" (Halaris \& Sloan, 1985). The search for computer literacy has its beginning in elementary school (Albee, 2003; Asan, 2003) and continues through high school. In addition, computer literacy has now become a global issue (Asan, 2003; Csapo, 2002).

Terms such as computer competency, computer proficiency, and computer literacy tend to be used interchangeably. Although each of these terms represents fundamental computer skills, this is not the end goal. The notion of information literacy builds upon computer literacy. As Murray (2003) points out, to be information literate, a person must be able to recognize when information is needed and have the ability to locate, evaluate, and use effectively the needed information. Vitolo \& Coulston (2002) also point out the link between information literacy and the use of information systems.

Regardless of the terminology--it is important that business students' computer skills improve as they move through their college education and that the skills they learn are what employers need them to have. The issue of who is responsible for ensuring literacy is decades old (Hartman, 1983) and even more important today.

\section{Problem Identification and Verification}

Since computer and information literacy are key attributes of well-prepared college graduates, the question of who is responsible for ensuring such literacy is important. For those universities or colleges that have an institutional computer literacy requirement, it seems clear that an interdisciplinary approach is best. For those institutions without an overall computer literacy requirement, 
the responsibility rests within the colleges/schools which do have such a requirement. This latter situation is the case for this paper. The ideas presented, however, are applicable to any setting.

All two-year and four-year degrees in the School of Business at UVSC require computer competency in one form or another as a prerequisite for matriculating into these programs, although this study focuses on students in the four-year Business Management degree. In order to meet this need, the Computer Information Systems (CIS) Department within the School of Business offers students a series of course modules that teach the techniques and concepts needed to pass these hands-on tests at a level of $80 \%$ or higher. Students who have learned these skills on their own or in high school may choose to take the production tests that must be passed at the same level of competency. By the end of their freshman year, most business students should have completed this computer proficiency requirement.

Business Management majors are also required to take a junior-level Management Information Systems course that is taught as a service course by the CIS Department. This course incorporates many activities that require students to use the applications found in the office suite to solve basic business problems or to conduct research and report their findings. Anecdotal evidence suggested to faculty teaching this course that many students were struggling with how to use these computer tools. Some remediation of skills was required to help students successfully fulfill assignments. This disparity in competency between freshmen and juniors prompted the authors to study the situation in more detail.

A subjective measurement of students' computer skill competency was given in the form of a survey administered to freshmen after they had completed their computer proficiency course, juniors in the Management Information Systems course, and seniors in a capstone course.

Several studies have shown that measures of student self-efficacy can provide meaningful and demonstrable outcomes assessment information to evaluators (Compeau \& Higgins, 1995; Karsten \& Roth, 1998; Wortham \& Harper, 2003). The same survey questions were also given to current employers of UVSC's business management majors. The student questions were framed to ask about their use and confidence in each of the following applications: word processing, spreadsheet, database, and presentations. The employer survey asked about their confidence in their employees to perform the needed skills in the same computer applications. The analysis of data from these surveys is shown in Figure 1.

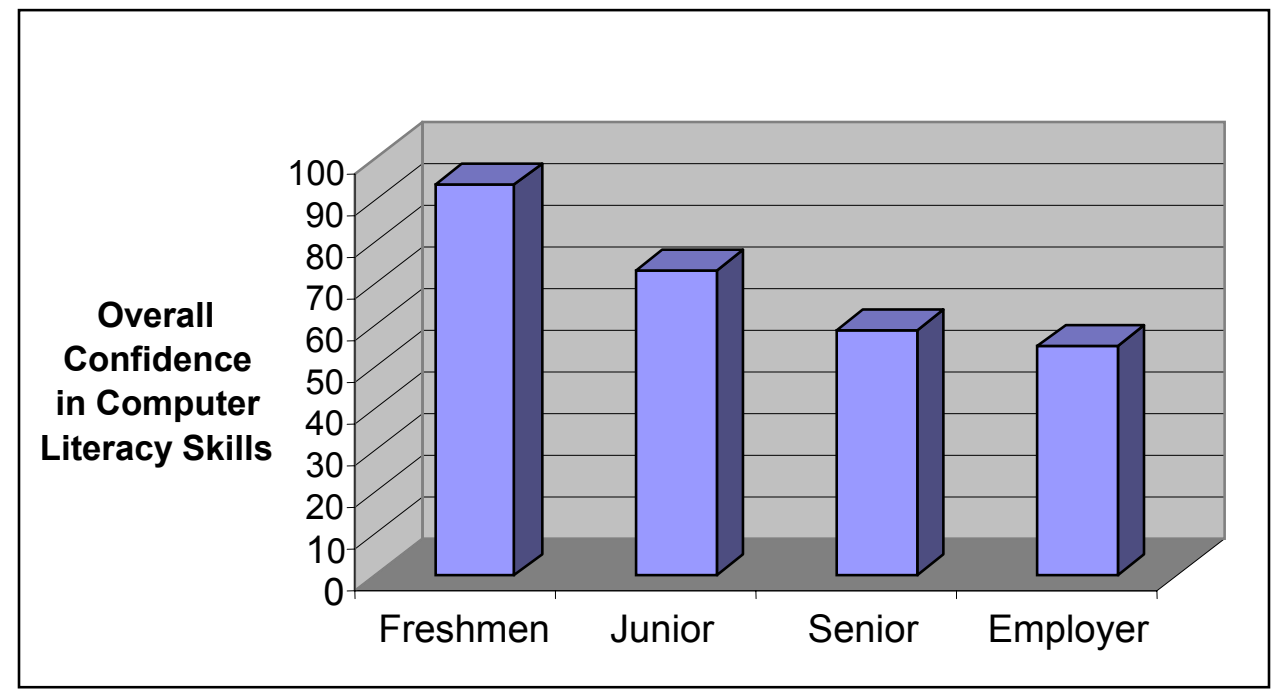

Figure 1: Declining Confidence in Computer Literacy Skills 
Improving Computer Literacy of Business Management Majors

The continuing decline in students' confidence in their computer literacy skills was a concern to faculty and the administration. Additional survey data where seniors in the School of Business were asked to self-report showed that, business management students reported only minimal usage of spreadsheets and databases in their business management core courses. The old adage of "Use it or lose it" seemed to apply to our search for computer literacy (Bartholomew, Johnson, Ormond, \& Mulbery, 2003).

As a follow-up to the survey data, the authors interviewed each faculty member teaching courses in the business management core. The results, shown in Table 1, confirmed the previous survey (Bartholomew, 2004).

Table 1: Usage Level of MS Office Applications in Business Classes

\begin{tabular}{|lrl|r|r|}
\hline Business Course Title & Word & Excel & Access & PowerPt \\
\hline Written Business Communication & 2 & 0 & 0 & 0 \\
Macroecomonics & 1 & 0 & 0 & 0 \\
Microecomonics & 1 & 0 & 0 & 0 \\
Business Statistical Apps & 1 & 0 & 0 & 0 \\
Organizational Behavior & 1.75 & 0 & 0 & 1.25 \\
Principles of Finance & 2 & 3 & 0 & 0 \\
Survey of International Business & 2 & 0 & 0 & 0.5 \\
Cross Cultural Communications & 2 & 0 & 0 & 1 \\
International Marketing & 2 & 0 & 0 & 1 \\
Human Resource Management & 2 & 0 & 0 & 1 \\
Managing Organizations & 2 & 0 & 0 & 1.5 \\
Operations Management & 2 & 0 & 0 & 1 \\
Principles of Marketing & 2 & 0 & 0 & 1 \\
Internet Marketing & 2 & 0 & 0 & 2 \\
Professional Portfolio Preparation & 2 & 0 & 0 & 1 \\
Business Policy & 2 & 3 & 0 & 2 \\
Executive Lecture Series & 1 & 0 & 0 & 0 \\
\hline Level Averages & 1.75 & 0.35 & 0.00 & 0.78 \\
\hline
\end{tabular}

Level Scale: 0- Not Used, 1: Novice, 2: Intermediate, 3: Advanced, 4: Expert

As can be seen, the MS Access database application was not used in any of the required business core courses and MS Excel spreadsheets could be used by students to complete assignments in two upper-division courses, but were not required. Every class required the use of MS Word and nearly two-thirds required the use of MS PowerPoint.

A survey of 53 prospective employers of business management graduates was also conducted to identify their needs for computer literacy. The results of this survey shown in Figure 2 confirm the findings of Dudley \& Dudley (1995). The use of spreadsheets and word processing are highest on the list. The creation of Web pages and the use of databases are the least important.

In addition to importance rating, employers were also asked to identify a skill depth level on a scale of $0-5$ (specific competencies were included for each level). Average depth levels in decreasing order were spreadsheets -2.00 , Internet -1.71 , Word Processing -1.46 , presentation graphics -1.14 , and database -1.14 . We also analyzed the data to see if there were differences between emphases within the Business Management Degree (Finance, Sales and Marketing, and Management). No statistically significant differences were found. 


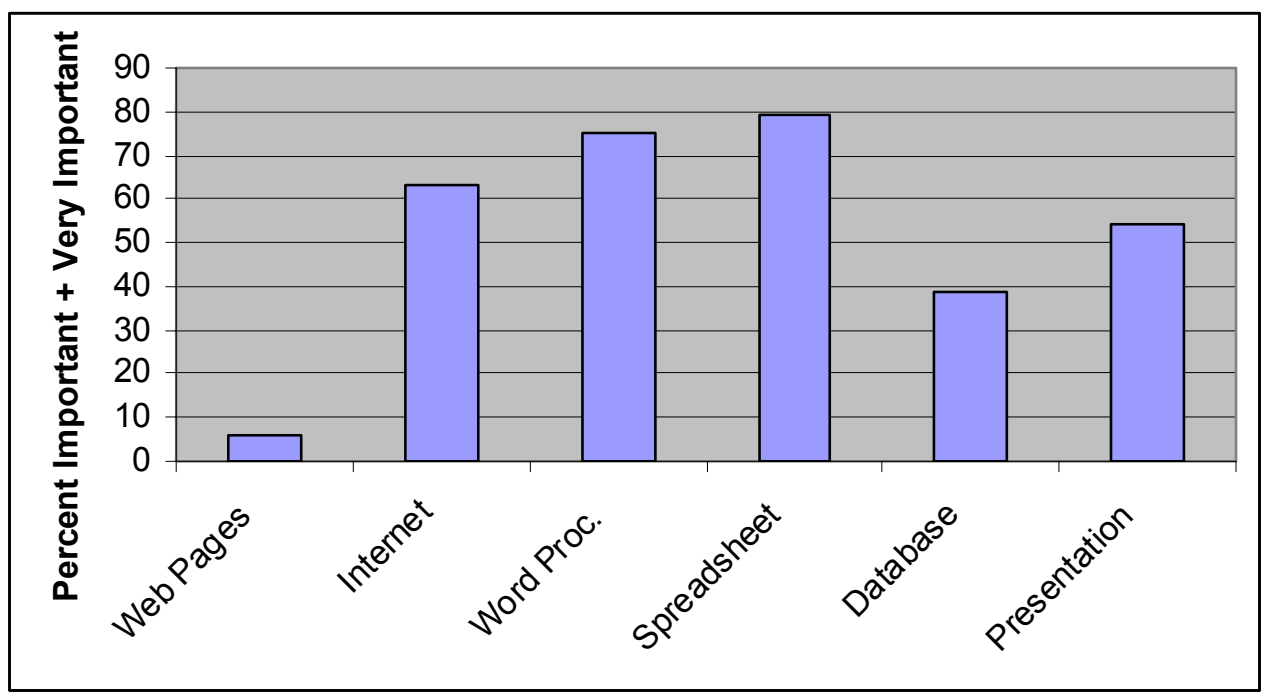

Figure 2: Employer Computer Literacy Needs

After analyzing the feedback from the employer survey on which computer competency application skills were most valued, the authors of this study chose to narrow the focus of our final objective evaluation of students to spreadsheet usage. Both business management students and business faculty reported high usage and performance level in word processing in all core classes.

A hands-on, Excel proficiency laboratory exercise was given to juniors in the MIS course. The exercise and scoring rubric were developed by a Ph.D. Information Systems professor to assess performance in basic Excel skills such as cell formatting, simple formulas, worksheet structure, summations, and basic chart creation. Student averaged $62 \%$ on this objective evaluation when they had demonstrated similar skills at a level of higher than $80 \%$ by passing their computer literacy Excel module as freshman. Interestingly enough, this instructor administered the same Excel proficiency exercise using the same scoring rubric to undergraduate business management majors at an AACSB Business School in the southern U.S. and student performance was shown to have no statistical difference when results were compared using a two-sample t-test assuming equal variances (Bartholomew et al.,2003). It seems that our Business School is not the only one having these issues.

\section{Identification of Needs and Goal Setting}

In key areas like spreadsheet and database usage, our study of the computer proficiency levels of business management majors showed a considerable deviation from one of the general competencies identified by the UVSC School of Business as being required of all graduates. In preparation for AACSB accreditation, a committee of department chairs from all departments in the UVSC School of Business deliberated and formulated a group of core competencies that should span all majors in the school. Figure 3 is a diagram representing the school's competencies in three areas, namely general competencies, business competencies, and discipline specific competencies. 


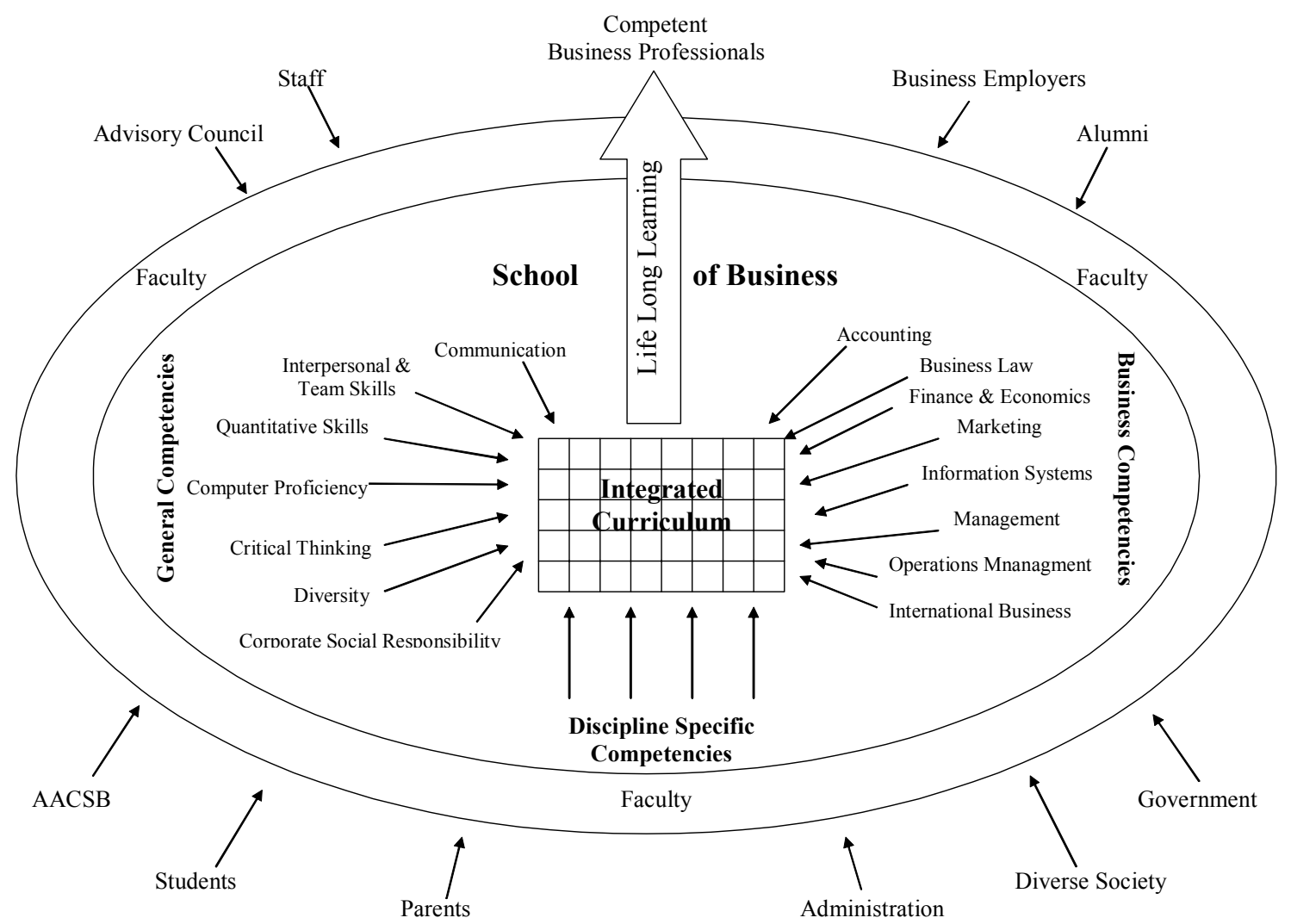

Figure 3: School of Business Objectives and Competencies

The diagram further indicates that each specific competency should be integrated across the curriculum, or as McCade (2001) points out, disciplines should consistently teach and reinforce such skills. The general competency which is the focus of this paper is computer proficiency. The UVSC School of Business further clarifies this need by giving a definition and a further breakdown to computer proficiency requirements of all business majors as shown in Figure 4.

$\begin{array}{ll}50 \text { Computer Proficiency } & \begin{array}{l}\text { Graduates will be proficient in the use of information tech- } \\ \text { nology to facilitate communication, collaboration, problem } \\ \text { solving, decision making, personal productivity, and life- } \\ \text { long learning. }\end{array} \\ & \begin{array}{l}\text { Have a basic understanding of how computers work and be } \\ \text { conversant with fundamental terminology used for describ- } \\ \text { ing computers and associated devices. }\end{array}\end{array}$

20 Windows Operating System Be able to operate MS Windows effectively to use various applications and manage electronic files.

30 Internet and E-Mail

Understand and be able to use the various capabilities of the Internet and E-mail systems for communication and collaboration.

40 Word Processing

Be able to use MS Word to create effective business documents.

50 Spreadsheets

Be able to create moderately complex MS Excel spreadsheets that help solve business problems. 
60 Database

70 Presentations

80 Information Retrieval
Be able to create a MS Access database containing several tables of business data and be able to generate appropriate queries and reports that provide information for business needs.

Be able to use MS PowerPoint to prepare effective visual slides for business presentations.

Understand how to use the Internet, library search tools, and document searching capabilities to locate relevant information to gain knowledge for work projects and decision making.

Figure 4: Definition and Breakdown of Computer Proficiency Competency Requirements for the UVSC School of Business

The International Society for Technology in Education (ISTE) in 2000 recommended integration of computer technology into content areas (McCade, 2001). Furthermore, as Eisenberg \& Johnson (2002) point out, "the end result of computer literacy is not knowing how to operate computers, but to use technology as a tool for organization, communication, research and problem solving."

It is abundantly clear from the data presented in the previous section that business management majors were not achieving the desired computer proficiency in the area of spreadsheets and that the proper integration of these skills was not occurring across the curriculum.

Obviously, something needed to be done. Our goal was to improve the computer literacy/proficiency of business management majors by building on the concepts and skills learned in the foundation class in other business classes across the curriculum. We would begin this process by increasing expectations and requirements for spreadsheet usage by students completing projects in core business management courses at our institution.

The purpose of this paper is to describe the approach to be taken in accomplishing this goal and to provide a procedural framework for others who may be faced with a similar problem. The first two steps of this framework have already been presented in this report: Problem Identification and Verification and Identification of Needs and Goal Setting.

The remaining steps of the framework include the following:

- Literature Review for Potential Solutions

- Formulating a Change Management Plan

- Determining an Implementation Schedule

- Assessment and Evaluation

These remaining four steps are described in the following sections of this paper.

\section{Literature Review for Potential Solutions}

Instead of reinventing the wheel, it was decided that our planned integration effort should examine the "best practices" being incorporated at other schools and then make the "best fit" for our specific needs. Many business schools are seeking to integrate competencies across the curriculum due to pressures from stakeholder groups such as accrediting bodies and employers. A literature review was undertaken to help identify such efforts. 
Improving Computer Literacy of Business Management Majors

\section{The Big6 - A Curriculum for the Integration of "Information Skills"}

The Big6 process is a curriculum that promotes information literacy strategies for effectively solving problems or conducting research in any discipline. The Big6 steps include task definition, information seeking strategies, location and access, use of information, synthesis and evaluation. (Eisenberg \& Johnson, 2002)

Each of these basic steps can be infused with the use of computer technology. According to Eisenberg \& Johnson, "when these steps are taught collaboratively with content area teachers in concert with content-area objectives, it serves to ensure that students are information literate." An abbreviation of the technology skills for information problem solving using the Big6 process follows:

1. Task Definition: communicate, brainstorm using software, groupware and communication tools.

2. Information Seeking Strategies: access electronic resources; generate flow charts, timelines, or projects plans.

3. Location and Access: locate computer resources; apply search strategies and technologies; conduct surveys; communicate with experts and referral services.

4. Use of Information: copy, paste and manipulate information; process and analyze statistical data; save and backup data gathered.

5. Synthesis: classify or group findings; model, simulate, compose and draft materials; generate reports, slideshows, web pages to present findings.

6. Evaluation: edit and revise work; apply ethical and legal standards to work; use communication technology to seek dissemination and critique of work.

One question the authors of this study needed answered was how computer literacy skills could be incorporated into courses where this had not been done in the past. During the process of surveying business faculty, many mentioned they did not require the use of computer skills in their assignments and projects because it didn't seem to fit their curriculum domain. But examining the Big6 process shows that any course that requires problem solving or a research project could easily use computer applications in any or all of the steps of the process. One of the participants of this study who teaches the Business Communications course immediately saw how he could begin to infuse his course with several of these Big6 steps.

\section{Training a Computer Literate Faculty}

Without a very rich home computing environment, students cannot achieve computer literacy without a computer literate faculty. Barbara Wolfe (1996) categorizes five levels of computer users: a person who can actually build new computer tools, tool adapters, tool users, tool abiders, and those who are indifferent to computer usage.

Wolfe suggests intensive application training in order to create a large body of tool users in the faculty. "Colleges and universities must develop a large body of faculty who are tool users and then capitalize on the few creative ones who can become adapters by providing them with proper incentives." (Wolfe, 1996) After initial training, there should be encouragement for exploration, testing and experimentation so a teacher can find ways that computer technology can be used in their specific functional area. 
The most important type of teachers needed in the battle to create computer literacy in students is tool adapters, that is, those who are very skilled in the use of the tool and can adapt/utilize it to fit the problem at hand. What faculty should become tool adapters? Wolfe suggests that tool adapters should be tenured faculty who are not burdened with a "publish or perish" mandate and who enjoy teaching and do not fear technology. The incentives and support for this group of faculty should be established from the highest level of administration. Several key faculty members could be directed to devise a curriculum that incorporates computer use in two or three key courses.

With a combination of release time and staff support, this revised curriculum could be developed, tested, and incorporated.

Finally, measures for assessing computer literacy/competency in business school graduates should be developed and put into place. If computer literacy is defined for specific functional areas of study, then students can be tested and surveyed to see if these criteria have been met. "[C]omputer literacy needs critical evaluation [from] the faculty in the discipline who are computer knowledgeable and can critique that competency." (Wolfe, 1996)

Whitaker \& Coste (2002) indicate that keeping up with technology places a high degree of stress on faculty member who see the institutions policies and support structure as inadequate. They suggest creating an Educational Technology Advisory Committee that is charged with supporting the adoption of IT across the campus. In addition to targeted IT training for faculty with the highest needs, they also suggest technology workshops, seminars, and presentations when faculty are already meeting for other purposes.

During the survey of business faculty conducted as part of this study, many faculty members expressed the need for training and support from the School of Business if they were to become solely responsible for integrating computer literacy skills into their courses. Because our School of Business already had a group of tool adapters, the CIS faculty, participating in computer literacy efforts in the school, it made sense to form a partnership between these more literate faculty and business faculty of key targeted courses. Raising the computer literacy level of the entire business faculty is a worthy goal and the School of Business administration expressed support for future training and workshops to begin this effort.

As part of ongoing AACSB accreditation efforts, outcomes assessment has become a critical need in evaluating the success of our programs and individual courses. The authors of this study agree with Wolfe, that without ongoing assessment by faculty who have the expertise to make a correct evaluation of the needed skills, a integrated computer literacy plan may not succeed. Yearly surveying of senior business management students has been added to our change management plan.

\section{Incorporating NETS Goals into a Curriculum}

The National Educational Technology Standards for Students (NETS) was a project that defined what computer literacy skills are needed by every student. This project was supported by the International Society for Technology in Education (ISTE), NASA, the U.S. Department of Education, the Milken Exchange on Education and Apple Computer. One goal of NETS was to differentiate between what was "nice to know" from what was "need to know" in computer literacy skills and knowledge.

McCade (2001) organizes the NETS goals according to who should be responsible for delivering each goal. An example would be the goal: Understanding social, ethical and human issues related to computer technology. The parties who should deliver this goal would be those involved in technology education: impacts of technology and all disciplines: teaching inquiry (information literacy). 
Improving Computer Literacy of Business Management Majors

The suggestions of those involved in the NETS computer literacy project to define core competencies needed by all students prompted one member of this study who served as a department chair to raise this need at the administrative level in our School of Business. The resulting product was a formalized diagram and list of competencies, including computer proficiency that could be integrated throughout the core business curriculum. Our Business School may have been in a uniquely motivated to complete this competency definition process because of AACSB accreditation efforts, but any other faculty could undertake a similar steps if they have the support of administration.

\section{Strategic Application of MIS Business Cases}

Several supplementary textbooks have been developed by publishers in the area of Management Information Systems (MIS) Cases. These MIS cases could be used in any business course where students are encouraged to use application software to solve managerial problems. The goal of these casebooks is to provide students with a realistic business problem where they are encouraged to choose from the computer software and tools at their disposal to apply their managerial problem solving skills. Some of the computer software skills covered by these case textbooks include Microsoft Access, Excel and PowerPoint.

Some current casebooks in this category are Problem-Solving Cases in Microsoft Access and Excel (Brady \& Monk, 2005), Application Cases in MIS: Using the Internet and Spreadsheet and Database Software (Morgan, 2002), and MIS Cases: Decision Making with Application Software (Miller, 2005). While these texts are marketed specifically for a MIS course, the cases could be applied in any related functional area. For example, a case that focuses on creating a cash flow worksheet could be used to supplement a finance course. Many of the cases presented have a difficulty rating, skills check, and provide an instructor with any needed data files and solution files.

At UVSC we have incorporated some of these problem-solving cases in our MIS course. Students are given the case background, information specification, and case deliverables are specified. Every semester cases are rotated out and new cases are added to the course. CIS faculty would be able to partner with other business faculty to help find and implement similar case exercises in their courses. One benefit of using these pre-packaged business cases is that they are tested and all the resource files are provided for the instructor. Faculty approached during our surveying process expressed willingness to make use of computer application exercises and materials if they didn't have to develop them. These MIS case textbooks would meet this need and still have flexibility to be used in several courses.

\section{Applying a Decision Model for Integration}

Many business schools, in response to pressures from key stakeholders like future employers, are recognizing a need to change the business curricula to better prepare their students with a new bundle of skills including technical skills. A study conducted by Hamilton, McFarland, and Mirchandani (2000) found that there were more than 20 different approaches being used by business schools to achieve cross-functional integration of specific competencies in the curriculum. These approaches could be grouped into two major categories: experiential learning and classroom learning.

Because there are so many approaches to integrating knowledge and skills in a curriculum, the main contribution of the work done by Hamilton et al. was to create a relationship among the various approaches, student /faculty/school learning goals and possible constraints. Because this is such a subjective process, whatever approach or combination of approaches a business school chooses, it will be helpful to see the recommended best fit for the local university environment 
(Hamilton et al., 2000). The integration method that best fit the goals and constraints of our constituencies at UVSC was the Just-In-Time method.

This Just-In-Time technique brings in skilled technology faculty or other training resources to teach hands-on skills just as needed at strategic places throughout the curriculum. This allows the host faculty member to plan and be part of this effort without having to deliver the technical instruction personally.

The computer literacy effort being conducted in the school of business at our institution will be aided by participation of faculty members in the CIS department who are current and skilled in both office suite software as well as applying computer skills to solve real-world business problems. Because this is such a subjective process, whatever approach or combination of approaches a business school chooses, it would be necessary to see that the recommended "best fit" for other schools matches their own goals and constraints to their own local university environments (Hamilton et al., 2000).

\section{Formulating a Change Management Plan}

This section summarizes the change management plan developed by the authors to increase the level of computer literacy in our business students. Like a good story that improves with the telling, this change management life-cycle would need to be adapted and fine-tuned to meet the specific situations and resources available at other institutions.

Our change management plan will use a life-cycle that includes the following steps:

Step 1: Identify a set of general computer literacy competencies for business students.

Step 2: $\quad$ Help students to build a foundation of computer office suite skills and providing a long-term training resource.

Step 3: $\quad$ Narrow the focus of our integration efforts to a single office suite skill.

Step 4: $\quad$ Choose an integration method that provides a "best fit" for the needs and resources of our business school.

Step 5: $\quad$ Identify the courses throughout our current business management curriculum where the targeted office suite skill will be reinforced through the use of strategically placed hands-on, real-world projects.

Step 6: $\quad$ Conduct outcomes assessment of student confidence and employer satisfaction.

The first and last steps in this process are most important and most often ignored. Without a welldefined set of competencies gathered from university stakeholders and without frequent and unbiased assessment, the resulting effort may miss the mark.

\section{Step 1: Identify Computer Literacy Competencies}

In 199912 of the higher education institutions in our state collaboratively developed a computer competency standard for business students. This process was necessary to ensure articulation among these institutions when students transfer credits. Students must pass hands-on production tests at 80 percent accuracy in six categories. Windows Operating System and General Computer Information, Word Processing, Spreadsheets, Database, Presentations, and Internet and E-mail (Bartholomew et al, 2003). This state business computer proficiency was used as the measure of a minimal level of computer literacy for business management students at UVSC. (See Figure 4) 


\section{Step 2: Provide Initial Skills Training and Long-Term Resources}

Institutions of higher education should provide students a computer literacy course early in their schooling. If your school includes this literacy as part of a general education requirement, your School of Business can participate in the process of defining course goals. If not, a School of Business should implement such a course within its own curriculum. Because the UVSC Business School programs had no room for a literacy course, we implemented this proficiency requirement as a prerequisite to matriculation in both our two-year and four-year programs.

Currently, as our students exit the Computer Literacy course, they can choose to keep their textbooks or lab manuals; but there is not a computer-based resource provided that they can consult when they wish to review for future course demands. As part of this computer literacy effort, it is recommended that a computer-based training (CBT) supplement such as the SimNet MIS (2004) or SAM (2005) Assessment \& Training be added as a requirement of this Computer Literacy course.

\section{Step 3: Narrow the Computer Literacy Focus to a Single Office Suite Application}

Hoffman, Blake, McKeon, Leone, and Schorr (2005) point out that applications such as word processing, e-mail, and the Internet are natural to most students and, hence, require less emphasis. When beginning to formulate a long-term goal of change to the business curriculum, a more narrowed computer literacy focus was obtained by examining the previously referenced employer survey asking which of the office suite skills were most needed by them. It was found that the largest gap between computer skill expectations and confidence and practice of our business graduates was in the use of spreadsheets to solve business problems. As your own institution evaluates your business students and the needs of your local employers, you may choose to focus on a different computer competency than spreadsheets.

\section{Step 4: Choose a "Best Fit" Integration Method}

Hamilton et al. (2000) found that there were many different approaches a business school could take when trying to integrate specific competencies across its core curriculum. Your institution should take advantage of examining each of these options and finding the "Best Fit" for your own requirements and environment. UVSC followed the steps outlined in this study and found that the "Just-In Time" option fit with our current faculty structure and political environment. We may need to evolve this strategy in the future, but for now we have begun this process for ourselves.

\section{Step 5: Targeting Business Courses for Intervention}

A survey of faculty teaching courses in the business management degree revealed that only the word processing and some presentation skills were being reinforced in every course. A difficult problem awaited us as efforts were made to examine solutions for strengthening other key computer literacy components of the Business Management curriculum. As Kim and Keith (1994) stated, "computer literacy cannot be learned effectively in one introductory course; rather, [it] must be accomplished through subsequent courses which both reiterate the basic knowledge and at the same time introduce more sophisticated applications of computer technology in specific discipline areas." The very skills that many companies are seeking in today's job market are the more complex application of computer literacy, like the ability to analyze challenges and opportunities, to communicate possible solutions, and the ability to motivate and coordinate fellow workers. 
When examining the list of courses that make up the four-year business degree, we found several key courses where spreadsheet skills could be reinforced through the use of hands-on exercises used to complement important concepts of these courses. Taking the advice of McCade (2001), "skills are best acquired in context of their practical application rather than taught separately and then applied later." As Jones (2001) points out, the first place that teachers look for technology help is their peers. Consequently, the authors volunteered their support to work with the other business management faculty to prepare and grade assignments and to help review spreadsheet concepts with students. A schedule of courses targeted for this technical upgrade will be implemented over the next two years beginning with the Macroeconomics course taught in the sophomore year and culminating with a Business Policies capstone course in the senior year. A detailed examination of a two-year integration plan for courses in the business curriculum at our institution will be provided in the next section.

\section{Step 6: Assessment of Student Confidence and Employer Satis- faction}

A measurement of the success or failure in any integration effort requires a thoughtful, frequent outcomes assessment. This ongoing assessment of computer literacy should be tied to the specific competencies outlined as a targeted goal in Step 3. A baseline assessment of students and employers was conducted at the beginning of this computer literacy effort (refer to student confidence results and employer survey results discussed previously). An outline of an assessment plan is presented in the section following the Implementation Schedule.

Over time, an additional step could be added that encourages a refinement of the process as needed to meet new market-driven demands in computer literacy. The International Society for Technology in Education (ISTE) (2000) recommended integration of computer technology into functional content areas stating that "the end result of computer literacy is not knowing how to operate computers, but to use technology as a tool for organization, communication, research and problem solving" (Eisenberg \& Johnson, 2002). The moving computer literacy target should be expected and accommodated in any reengineering of the targeted goals of this change management plan.

\section{Determining an Implementation Schedule}

The timeframe for implementing more computer-related assignments in the Business Core classes would take two years. Each semester two or more classes would be added based on the following schedule: In the first semester, MGMT 2200, Written Business Communication, and MGMT 2300, Macroeconomics, would begin the process. In the second semester, MGMT 2310, Microeconomics, and ACC 2010, Financial Accounting, would be added. In the third semester, MGMT 3600, Principles of Marketing, ACC 2020, Managerial Accounting, and MGMT 3450, Operations Management, would be added. Finally, in the fourth semester, MGMT 3100, Principles of Finance, and MGMT 4800, Business Policy, would be added.

By following this timeframe the authors will have the time to work with the Business Management faculty and the Finance and Economics faculty to develop new computer-related assignments and prepare them with the skills they will need to present the material effectively. The authors of this study have enlisted the support of the School of Business administration, department chairs, and mentors of courses scheduled for the first-year implementation. We realize that faculty have the right to academic freedom in their classrooms. Luckily, we have only experienced positive attitudes as we surveyed business faculty and they were made aware of the results of our 
Improving Computer Literacy of Business Management Majors

evaluations. It was determined that trying to implement the additional computer-related assignments for all core classes at once would spread the support faculty too thin.

\section{Ongoing Assessment is the Key to Success}

The purpose of assessment is to help identify problems. As Whittaker \& Coste (2002) point out, it is also to help determine if efforts to correct problems have been successful and, as such, must be an ongoing effort. The interventions described in the previous section should have a positive effect on the computer literacy skills of business management majors. To determine if this has, indeed, been the case, data needs to be collected from graduating seniors which measures the extent of their computer literacy skills.

Ideally, each graduating senior would be given an objective computer literacy exit exam, such as those discussed by Wallace \& Clariana (2005), which tests the various competency components of the school's computer proficiency requirement. In addition, the other general competencies shown in Figure 3 should also be tested. The logistics of such an exam, however, make it practically infeasible. A more workable alternative to such an exam would be to utilize an exit survey which elicits students' perceptions of the extent to which they possess the general competencies required of all graduating business students.

The need for both objective and self-appraisal testing has been previously recognized (van Vliet, Klutke, \& Chakraborty, 1994). Their research indicates, however, that self-appraisal tests are typically more lenient indicators of performance than objective tests. Bartholomew et al. (2003) suggests that such self-appraisal skill indicators can be as much as 20 points higher than an actual objective exam. The research of Karsten \& Roth (1998) and Compeau and Higgins (1995), however, suggest that measures of student computer self-efficacy can contribute meaningful and demonstrable outcomes assessment information.

Since senior business management majors were already being assessed by an exit examination covering the general business competencies shown in Figure 3, it was decided to add a survey of questions to assess their self-appraisal pertaining to computer literacy and the other general competencies required. If the interventions suggested in the previous sections were indeed efficacious, then pertinent self-appraisal scores should increase over time.

To this end, a survey instrument was developed to accomplish the assessment (See Appendix A). The survey will be given each semester to business management students in the Policy Course. The initial survey results will serve as baseline measures. After two years, students who have been exposed to the computer literacy interventions described earlier will be taking the survey. Data from the next two years will then be compared against the baseline data. Employers' satisfaction with our business management graduates computer proficiency is another important factor that should be accessed. A survey will be given to current employers of our graduates at this twoyear point. Participants of this study will want to know what computer skills they value as well as the satisfaction and confidence they have in the abilities of our graduates.

\section{Conclusion}

This paper has presented a case study describing ongoing efforts being conducted at Utah Valley State College, in the School of Business, for improving computer literacy of business management majors. The impetus for this research was the discovery that students reported decreasing confidence in their computer skills as they progressed through their academic program. The reason for this decline was attributed to the fact that, except for word processing, business management faculty were generally not requiring the use of the basic computer tools in their courses. A survey of employers of the graduates, however, found that computer literacy skills at the interme- 
diate level were important, especially the use of spreadsheets. The declining levels of students' key computer literacy skills was also contrary to the general computer literacy competency requirements defined by the school as being required of all graduating students. As with the emperor and his new clothes (Bartholomew, 2004), something needed to be done.

Following a review of the relevant literature, the authors formulated a change management plan based on the best practices found in the literature that were consistent with the needs and culture of their environment. The authors concluded that the solution to this problem would depend on the support and cooperation of the Business Management faculty. These faculty members would need to require their students to do assignments that would involve them in using the computer applications and apply the concepts and skills they learned in previous computer classes. Also, these faculty members would have to be computer literate themselves so they could model skills, techniques, and behaviors to produce computer-literate graduates.

A set of specific courses were identified for intervention and a two-year timeline established for the authors to work with appropriate faculty to integrate spreadsheet exercises into their course assignments. In addition, an ongoing assessment approach was defined, as part of an existing senior exam and survey of employers, to determine if the intervention was successful and the desired computer literacy goals were being achieved.

Since this is a forward-looking paper, the results of the implementation of the framework will need to wait for a follow-up paper after two years. The conclusion of the paper is that there are numerous examples of best practices at other institutions, as described in the literature, which can be used to improve computer literacy. It is hoped that the procedural framework described in this paper may also contribute to others in obtaining this goal.

\section{References}

Albee, J. (2003). A study of preservice elementary teachers' technology skill preparedness and examples of how it can be increased. Journal of Technology and Teacher Education, 11(1), 53-71.

Asan, A. (2003). Computer technology awareness by elementary school teachers: A case study from Turkey. Journal of Information Technology Education, 2, 153-164. Available at http://jite.org/documents/Vol2/v2p153-164-109.pdf

Bartholomew, K, Johnson, D., Ormond, P., \& Mulbery, K. (2003). Computer literacy: Use IT or lose it! Utah Valley State College School of Business Journal, 1, 6-14.

Bartholomew, K. (2004). Computer literacy: Is the emperor still exposed after all these years? Journal of Computing Sciences in Colleges, 20(1), 323-331.

Brady, J. A. \& Monk, E. F. (2005). Problem-solving cases in Microsoft Access and Excel. Boston, MA: Thomson Course Technology.

Compeau, D. \& Higgins C. (1995). Computer self-efficacy: Development of a measure and initial test. MIS Quarterly, June, 189-211.

Csapo, N. (2002). Certification of computer literacy. T H E Journal, 30(1), 41-49.

Dudley, S. \& Dudley, L. (1995). New directions for the business curriculum. Journal of Education for Business, 70(5), 305-310.

Eisenberg, M. \& Johnson, D. (2002). Learning and teaching information technology skills in context. ERIC Digest, September, 1-4.

Halaris, A. \& Sloan, L. (1985) Towards a definition of computing literacy for the liberal arts environment. ACM SIGCSE Bulletin, Proceedings of the sixteenth SIGCSE technical symposium on Computer science education SIGCSE '85, 17(1), 320-326. 
Improving Computer Literacy of Business Management Majors

Hamilton, D., McFarland, D. \& Mirchandani, D. (2000). A decision model for integration across the business curriculum in the 21st. century. Journal of Management Education, 24(1), 102-127.

Hartman, J. (1983). Computer literacy objectives for college faculty, Proceedings of the 11th annual ACM SIGUCCS conference on User services, New Orleans, Louisiana, United States, 189-192, October.

Hoffman, M. \& Blake, J. (2003). Computer literacy: Today and tomorrow. Journal of Computing Sciences in Colleges, 18(5), 221-233.

Hoffman, M., Blake, J., McKeon, J., Leone, S., \& Schorr, M. (2005).A critical computer literacy course. Journal of Computing Sciences in Colleges, 20(5), 163-175.

International Society for Technology in Education (ISTE) (2000). National educational standards for students-connecting curriculum and technology. Eugene, OR. Web site available at http://www.iste.org/template.cfm

Jones, C. (2001). When teachers' computer literacy doesn't go far enough. Education Digest, October, 5761.

Karsten, R. \& Roth, R. (1998). Computer self-efficacy: A practical indicator of student computer competency in introductory IS courses. Informing Science: The International of an Emerging Transdiscipline, 1(3), 61-68. Available at http://inform.nu/Articles/Vol1/v1n3p61-68.pdf

Kim, S. \& Keith, N. (1994). Computer literacy topics: A comparison of views within a business school. Journal of Information Systems Education, 6(2), 55-59.

McCade, J. (2001). Technology education and computer literacy. The Technology Teacher, October, 9-13.

Miller, L. M. (2005). MIS cases: Decision making with applications software. Upper Saddle River, NJ: Prentice-Hall.

Morgan, J. N. (2002). Application cases in MIS: Using the internet and spreadsheet and database software. New York, NY: McGraw-Hill/Irwin.

Murray, J. (2003). What is “contemporary literacy?” Multimedia Schools, 10(2), 15-18.

Owens, B. (2003). Ethics and the Internet: A novel approach to computer literacy. Journal of Computing in Small Colleges, 18(4), 4-10.

SAM Assessment \& Training (2005). Thomson Course Technology. Retrieved March 3, 2006, from http://www.course.com/events/conference2005/SAM.cfm

SimNet MIS (2004). McGraw- Hill College. Retrieved March 3, 2006, from http://www.mhhe.com/cit/simnet/

van Vliet, P., Klutke, M., \& Chakraborty, G. (1994). The measurement of computer literacy: A comparison of self-appraisal and objective tests. International Journal of Human Computer Studies, 40, 835-857.

Vitolo, T. \& Coulston, C. (2002). Taxonomy of information literacy competencies. Journal of Information Technology Education, 1(1), 43-52. Available at http://jite.org/documents/Vol1/v1n1p043-052.pdf

Wallace, P. \& Clariana, R. (2005). Perception verses reality - Determining business students' computer literacy skills and need for instruction in information concepts and technology. Journal of Information Technology Education, 4, 141-151. Available at http://jite.org/documents/Vol4/v4p141151Wallace59.pdf

Whitaker, B. \& Coste, T.G. (2002). Developing an effective IT integration and support system. Journal of Information Technology Education, 1(1), 53-63. Available at http://jite.org/documents/Vol1/v1n1p053-064.pdf

Wolfe, B. (1996). Achieving computer literacy. ACM SIGUCCS Newsletter, 26(3-4), 29-32.

Wortham, K, \& Harper, V. (2003). Learning Outcomes Assessment. Retrieved July 8, 2003, from www.aacsb.edu/knowledge services/LearningOutcomes.pdf. 


\section{Appendix A}

Questions used to measure students' assessment of computer literacy.

For each of the following, please indicate your personal, honest assessment of the level of confidence you have in your ability to accomplish each of the following:

1. Go to a computer store to select a personal computer and discuss intelligently the various components, functions, and devices you would like for your system?
a) No Confidence
b) Little Confidence
c) Moderate Confidence
d) High Confidence

2. Generate a basic Word document (with correct spelling and grammar) such as a letter or a memo containing formatting such as underlining, bolding, bulleted lists, and indents?
a) No Confidence
b) Little Confidence
c) Moderate Confidence
d) High Confidence

3. Generate a complex Word document such as a paper or a report containing tabs, tables, graphics, references, and headers and footers with page numbers.
a) No Confidence
b) Little Confidence
c) Moderate Confidence
d) High Confidence

4. Generate a basic Excel spreadsheet containing a title, row and column headings, numeric and alphanumeric data, simple formulas, and totals?
a) No Confidence
b) Little Confidence
c) Moderate Confidence
d) High Confidence

5. Generate a complex Excel spreadsheet containing functions, absolute references, references to other sheets, ranges, sorted lists, filters, and graphs or charts generated from the data?
a) No Confidence
b) Little Confidence
c) Moderate Confidence
d) High Confidence

6. Create an Access database containing several tables with primary keys specified, enter data into the tables, generate queries which select a subset of rows and columns from several tables, and generate reports using the report wizard?

a) No Confidence b) Little Confidence c) Moderate Confidence d) High Confidence

7. Create a Power Point presentation using various types of slides, various backgrounds, figures generated with the drawing tool, various transitions and builds, and custom animation?

a) No Confidence b) Little Confidence c) Moderate Confidence d) High Confidence 


\section{Biographies}

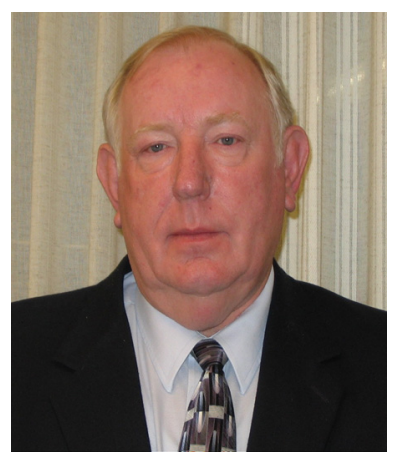

David W. Johnson received his Doctorate of Philosophy Degree in Industrial \& Operations Engineering and Business Administration from The University of Michigan. He currently holds the InfoTrax Systems Professor of Information Systems, teaches courses in Information Systems \& Technology, and serves as Chair of the Technology Management Department at Utah Valley State. He taught previously at Florida Gulf Coast University and at Western Michigan University and has considerable industry experience in information technology. His expertise includes strategic business and IT planning, systems analysis and design, and database management. His research interests include project management, knowledge management, and the use of IT to support teaching and learning. Dr. Johnson has published numerous journal articles and conference papers in the IS/IT arena.

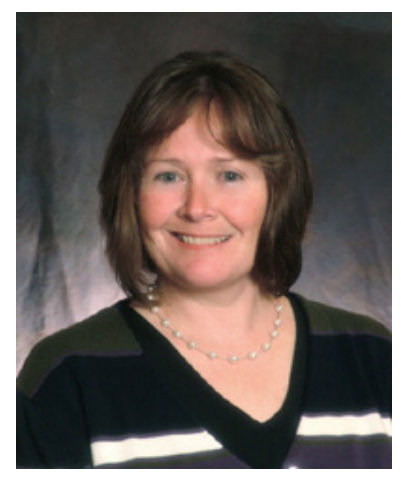

Kimberly W. Bartholomew received both her Bachelors and Masters degrees in Computer Science from Brigham Young University. She is currently an associate professor in the Information Systems \& Technology department at Utah Valley State College. Kim has been teaching in at UVSC for 12 years and during that time her department has changed names five times: CSIS, IS, BCIS, CITE and now IS\&T. Her teaching areas of emphasis include web development, e-commerce, MIS, and programming. Kim has published articles on ComputerBased Instruction, and computer literacy.

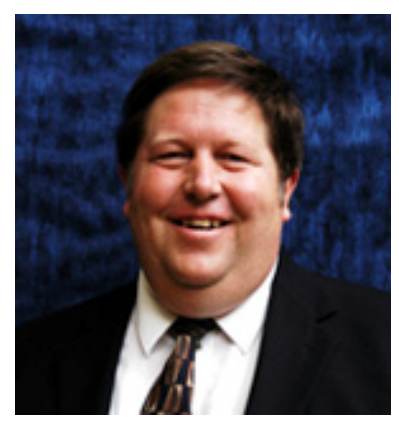

Duane Miller is a Professor of Business Management at Utah Valley State College. He completed a master's degree in business education and administrative management at Brigham Young University. He has taught marketing, business management, business communication, and human resource management classes for the last 24 years. He has managed several businesses and done extensive writing of textbook chapters and case studies. His research interests include pedagogy and change in the work place. Duane and his family live in Provo, Utah. 